\title{
Prenatal Niemann-Pick Disease: Biochemical and Histologic Examination of a 19-Gestational Week Fetus
}

\author{
Edward L. Schneider, William G. Ellis, Roscoe O. Brady, John R. McGulloch, \\ and Charles J. Epstein ${ }^{[45]}$ \\ Departments of Pediatrics and Psychiatry, University of California, San Francisco, and Langley Porter Neuropsychiatric Institute, California \\ Department of Mental Hygiene, San Francisco, California, and the National Institute of Neurological Diseases and Stroke, \\ National Institutes of Health, Bethesda, Maryland, USA
}

\begin{abstract}
Extract
Prenatal diagnosis of Niemann-Pick disease was confirmed by deficiency of sphingomyelinase activity and increase in sphingomyelin content in the liver of an affected fetus. Morphologic findings included cellular enlargement with cytoplasmic vacuolization and eccentric nuclei on light microscopy, increased deposition of phospholipids demonstrated by lipid histochemistry, and increased acid phosphatase activity by enzyme histochemistry.

When visualized under electron microscopy, lipid cytosomes characteristic of the sphingolipid storage diseases were seen in hepatocytes, splenic cells, the endothelium and pericytes of cerebral vessels as well as in occasional neurons. Sphingolipid accumulation and morphologic findings indicate that biochemical and pathologic manifestations are well advanced in organs destined to produce the earliest clinical signs.
\end{abstract}

\section{Speculation}

Early pathologic manifestations observed in a 19-gestational week fetus suggest that any peri- or postnatal therapy devised for Niemann-Pick disease, Type A is likely to be ineffective unless it can reverse the already existing central nervous system damage.

\section{Introduction}

The advent of diagnostic amniocentesis coupled with therapeutic abortion has recently allowed investigators the opportunity to examine the earliest stages of human metabolic diseases. This report presents information obtained from biochemical and morphologic examination of a 19-gestational week fetus with Nie-
mann-Pick disease (NPD), Type A. This disease results from a deficiency of the catabolic enzyme, sphingomyelinase, that leads to accumulation of its substrate, sphingomyelin $[8,33]$. In liver, spleen, and other tissues, lipid-filled foam cells are seen on light microscopy [19] and sphingomyelin-containing cytoplasmic bodies are found on electron microscopy [17]. 
Parents of a normal 3-year-old girl and a boy who died at age $4.5 \mathrm{yr}$ with type A NPD were referred to our clinic because of their desire to have another unaffected child. The original diagnosis of NPD was based on a clinical course of neurological deterioration with hepatosplenomegaly, and an analysis of tissue obtained by liver biopsy which demonstrated a marked increase in sphingomyelin content $(9.38 \%$ of the fresh liver weight). After informed consent was obtained, diagnostic amniocentesis was performed at 13 gestational weeks, and sphingomyelinase activities of the cultured amniotic fluid cells from the fetus at risk were found to be less than $10 \%$ of control enzyme activities in parallel normal amniotic fluid cell cultures $(0.24$ and 0.53 nmoles/mg protein/hour versus 8.7 and 8.9) [14]. Prenatal diagnosis of NPD was made from these findings and, at the request of the parents, a therapeutic abortion was performed. Liver, spleen, and brain tissues from the NPD fetus and age-matched control fetuses were analyzed by multiple histologic and biochemical techniques.

\section{Materials and Methods}

\section{Enzyme Assays}

Sphingomyelin- ${ }^{1+} \mathrm{C}$ labeled in the choline portion of the molecule and glucose-1 ${ }^{14} \mathrm{C}$ cerebroside were synthesized chemically [18]. Tissue specimens were dehydrated with acetone, and enzymes were extracted with a solution of $0.01 \mathrm{~m}$ potassium phosphate buffer $(\mathrm{pH}$ 6.0 ) that contained $5 \mathrm{mg}$ sodium cholate $/ \mathrm{ml}$. Sphingomyelinase activity was determined at $\mathrm{pH} 5.0$ and glucocerebrosidase was measured at $\mathrm{pH} 6.0$ according to previously published procedures $[9,10,18]$.

\section{Thin-Layer Chromatography}

Lipids extracted from samples of fetal liver were separated by thin-layer chromatography on Silica Gel G using chloroform-methanol-water $(65: 25: 4, \mathrm{v} / \mathrm{v} / \mathrm{v})$ as the developing solvent [6]. Phospholipids were visualized with molybdate spray reagent [13]. Sphingomyelin was quantitated by measuring the phosphorus content of the eluted phospholipids [35].

\section{Histologic and Histochemical Preparations}

All tissues from the NPD fetus and from two agematched normal fetuses were fixed or frozen within 1-2 $\mathrm{hr}$ of termination of pregnancy by hysterotomy. Paraffin sections of formalin-fixed brain, spinal cord, liver, spleen and other viscera were stained with hematoxy- lin-eosin (HE), cresyl violet, Sudan black, periodic acidSchiff (PAS) with and without diastase digestion, and either Luxol fast blue (LFB)-cresyl violet or LFB-PAS. Nervous system tissue was stained by Mahon's myelin method, and liver and spleen were stained by Laidlaw's reticulin stain with $\mathrm{HE}$ or PAS counterstains. Frozen sections of formalin-fixed tissues were stained with oil red O, Sudan black, Nile blue sulfate, LFB, acid hematein (phospholipids) with and without sodium hydroxide hydrolysis [3], osmium tetroxide-alpha naphthylamine (OTAN) (phospholipids and cholesterol esters) with and without $\mathrm{NaOH}$ hydrolysis [3], perchloric acid-naphthoquinone [3], and the Schultz methods (cholesterol and cholesterol esters).

Liver, spleen, and multiple areas of brain and spinal cord were fixed in $3.5 \%$ phosphate-buffered glutaraldehyde $(\mathrm{pH} 7.3)$, post-fixed in $1 \%$ phosphate-buffered osmium tetroxide, and embedded in Araldite. One micron-thick Araldite sections for light microscopy were stained with crystal violet or Paragon multiple stain [26]. Ultra-thin sections were stained with lead citrate and uranyl acetate for electron microscopy [41]. Slices of glutaraldehyde-fixed liver were transferred after 2.5 hr to $6.8 \%$ phosphate-buffered sucrose for enzyme histochemistry. Liver acid phosphatase was localized by light and electron microscopy with the Gomori method using sodium $\beta$-glycerophosphate and lead citrate [15] and by light microscopy with the azo dye method using naphthol AS-TR phosphate and diazotized pararosanilin [5]. Incubation times ranged from 15 to $120 \mathrm{~min}$. Control sections were incubated in medium without substrate and in medium that contained $0.01 \mathrm{~m}$ sodium fluoride.

\section{Results}

\section{NPD Fetal Measurements}

Measurements of the NPD fetus were as follows: length, $27.5 \mathrm{~cm}$; weight, $416.5 \mathrm{~g}$; liver, $18 \mathrm{~g}$; brain, 66 $\mathrm{g}$; and kidneys, $4.5 \mathrm{~g}$. All these measurements are compatible with previously published values [31].

\section{Enzyme Assays}

Sphingomyelinase activities were undetectable in both NPD fetal liver and brain while glucocerebrosidase activities, examined as control enzyme activities, were comparable in NPD and control fetal tissues. These values, which have previously been reported [14], are presented in Table I. 
Table I. Biochemical findings in Niemann-Pick disease

\begin{tabular}{lcc}
\hline & $\begin{array}{c}\text { Fetus with Niemann- } \\
\text { Pick disease }\end{array}$ & Control fetuses \\
\hline Sphingomyelinase ${ }^{1,2}$ & & \\
$\quad$ Cultured amniotic & 0.24 & 8.7 \\
$\quad$ fluid cells & 0.53 & 8.9 \\
Fetal liver & 0.0 & 6.3 \\
$\quad$ Fetal brain & 0.0 & 9.0 \\
Sphingomyelin & & 1.4 \\
$\quad$ Fetal liver & 14.6 & 0.86 \\
Cholesterol & & 1.91 \\
$\quad$ Fetal liver & 1.50 & 1.08 \\
\hline
\end{tabular}

1 In nanomoles per milligram protein per hour.

${ }^{2}$ From Epstein et al. [14].

${ }^{3}$ In milligrams per gram wet weight.

\section{Thin-Layer Chromatography}

Quantitative measurements of the sphingomyelin extracted from NPD fetal liver revealed $14.6 \mathrm{mg}$ sphingomyelin/g wet weight versus 0.86 and 1.41 for two control fetal livers (Table I). Cholesterol content of the NPD fetal liver was not significantly different from levels in two control fetal livers $(1.50 \mathrm{mg} / \mathrm{g}$ wet weight versus 1.08 and 1.91) (Table I).

\section{Light Microscopy}

Neurons at all levels of the central nervous system showed no lipid storage or cytoplasmic distortion and liver and spleen contained no typical NPD foam cells. Hepatocytes in the NPD fetus contained smaller and more eccentric nuclei, increased amounts of vacuolated cytoplasm, more large dense cytoplasmic granules, and less glycogen than did normal fetal hepatocytes, whereas Kupffer cells were normal in size. In the NPD spleen, many round, moderately enlarged reticulum cells in the pulp cord and a few sinusoid endothelial cells contained eccentric nuclei and increased amounts of eosinophilic, refractile, and occasionally vacuolated cytoplasm.

\section{Lipid Histochemistry}

Hepatocytes from the NPD fetus, when compared with normal fetal hepatocytes, contained greater numbers of larger and more densely stained cytoplasmic granules when examined with the LFB, Sudan black, acid hematein, $\mathrm{NaOH}$-acid hematein, OTAN, and $\mathrm{NaOH}-\mathrm{OTAN}$ methods. Pyridine extracted most of the hematein-staining material, and thus confirmed its lipid nature. NPD hepatocytes contained only slightly increased amounts of cholesterol as determined by the perchloric acid-naphthoquinone method, but the amounts seemed normal with the OTAN and Schultz methods. The enlarged splenic reticulum cells stained more intensely with Sudan black and acid hematein than did adjacent cells of normal size or reticulum and endothelial cells of normal fetal spleen. Lipid stains of central nervous system showed no significant difference between NPD and normal fetuses in neurons, neuropil, myelinated tracts, or vasculature.

\section{Electron Microscopy}

In each of the hepatocytes examined in the NPD fetus, 5-20 round or oval lamellated lipid cytosomes (LC) were found (Fig. 1). When compared with the control normal hepatocytes (Fig. 2), NPD hepatocytes also contained increased numbers of mitochondria and decreased amounts of glycogen. Scattered Kupffer cells contained one or two LC's.

The LC's contained fine, undulating, occasionally parallel membranes which often ran as pairs or triplets and abutted on the cytosome-limiting membrane. Several of the larger LC's were lobulated and contained clusters of dense granular material associated with irregular vacuoles (Fig. 3). Many reticulum cells in the splenic pulp cords and venous sinusoid endothelial cells contained numerous LC's filled with coarse, densely stained membranes (Fig. 4).

Rare neuronal perikarya in the basal ganglia of the NPD brain contained LC's of variable density and complexity (Fig. 5) while other neurons contained dilated endoplasmic reticulum cisternae filled with moderately dense granular material. Occasional axonal processes in the basal ganglia and brain stem were distended with altered mitochondria and irregular dense bodies, often with membranous substructure (Fig. 6). LC's were observed in endothelial cells and pericytes of almost every vessel examined in the brain and spinal cord (Fig. 7).

\section{Enzyme Histochemistry}

By light microscopy, with both azo dye and Gomori lead methods, NDP hepatocytes consistently contained more acid phosphatase reaction product than did normal fetal hepatocytes. Electron microscopy, with the Gomori lead method, demonstrated that this product was within lipid cytosomes either along limiting membrane inner surfaces in the dense granular material within vacuoles, or linearly arranged along the cytosome lamellations. In normal hepatocytes, the acid phosphatase reaction product was localized in peribiliary dense bodies. Control sections of liver from NPD 


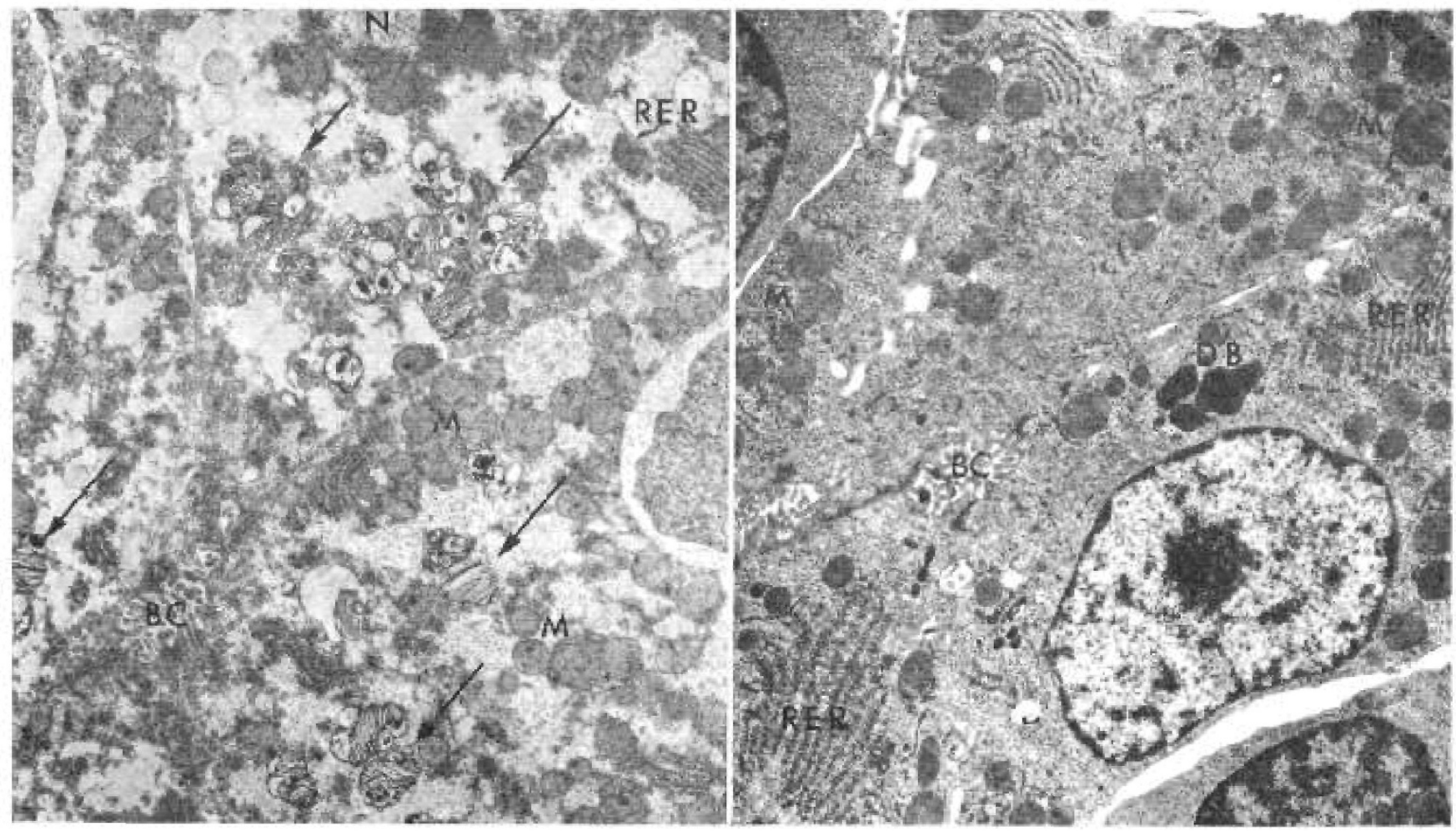

Fig. 1. Liver of fetus with Niemann-Pick disease. Survey electron micrograph. Lamellated lipid cytosomes (arrows) appear midway between nucleus $(N)$ and cell border. Hepatocytes are clustered around a bile canaliculus $(B C)$. Rough endoplasmic reticulum $(R E R)$ is relatively well preserved, and mitochondria $(M)$ are increased in number in comparison with normal hepatocytes $(c f$, Figure 2$) . \times 12,000$.

Fig. 2. Liver of normal fetus. Survey electron micrograph. Hepatocytes grouped around the bile canaliculus $(B C)$ contain rough endoplasmic reticulum $(R E R)$, mitochondria $(M)$, and dense bodies $(D B)$, but no lamellated cytosomes. $\times 13,000$.

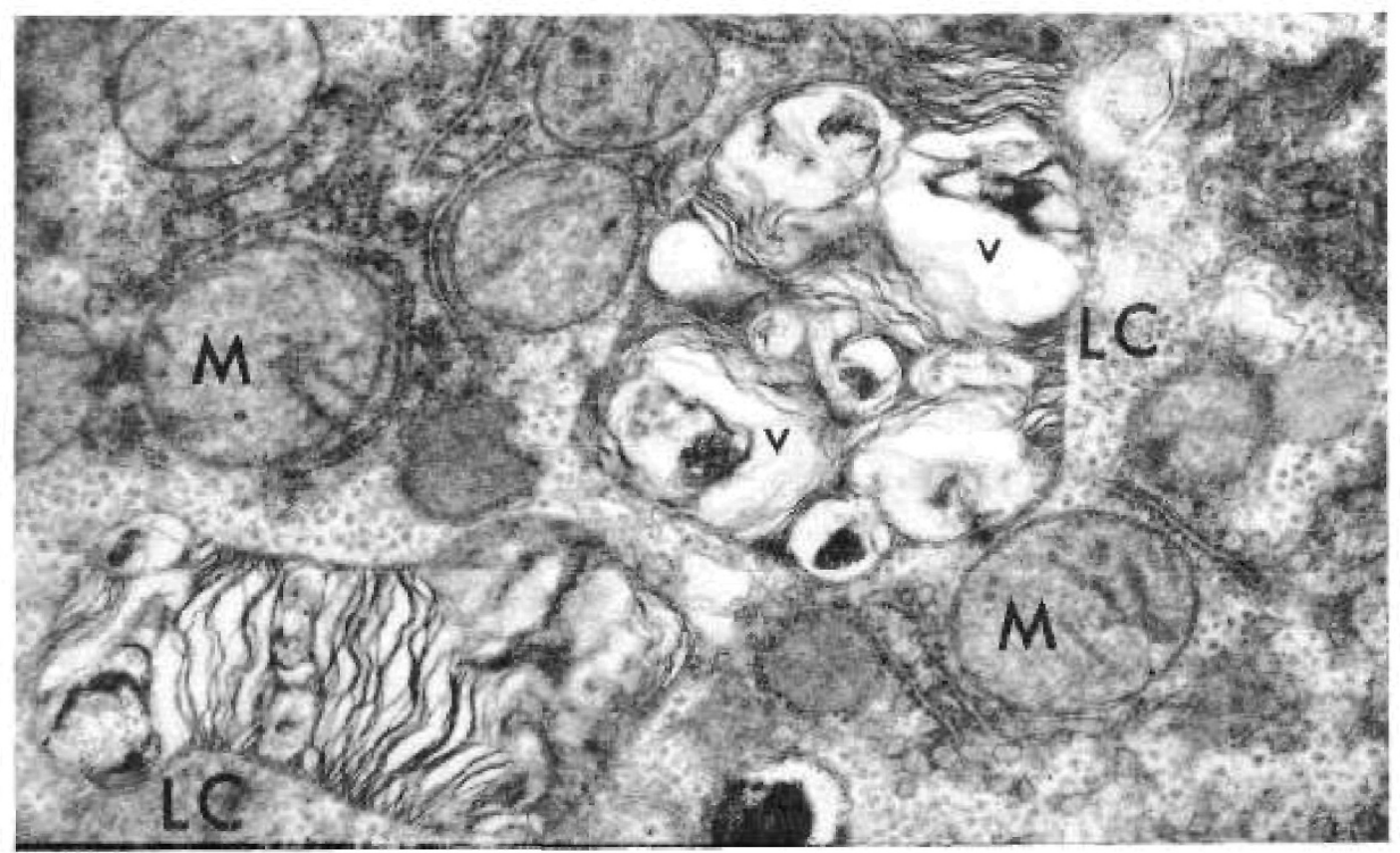

Fig. 3. Liver of the fetus with Niemann-Pick disease. Lipid cytosomes $(L C)$ contain fine wavy membranes. Vacuoles (V) within the cytosomes often contain dense granular material. $M$ : mitochondria. $\times 28,500$. 


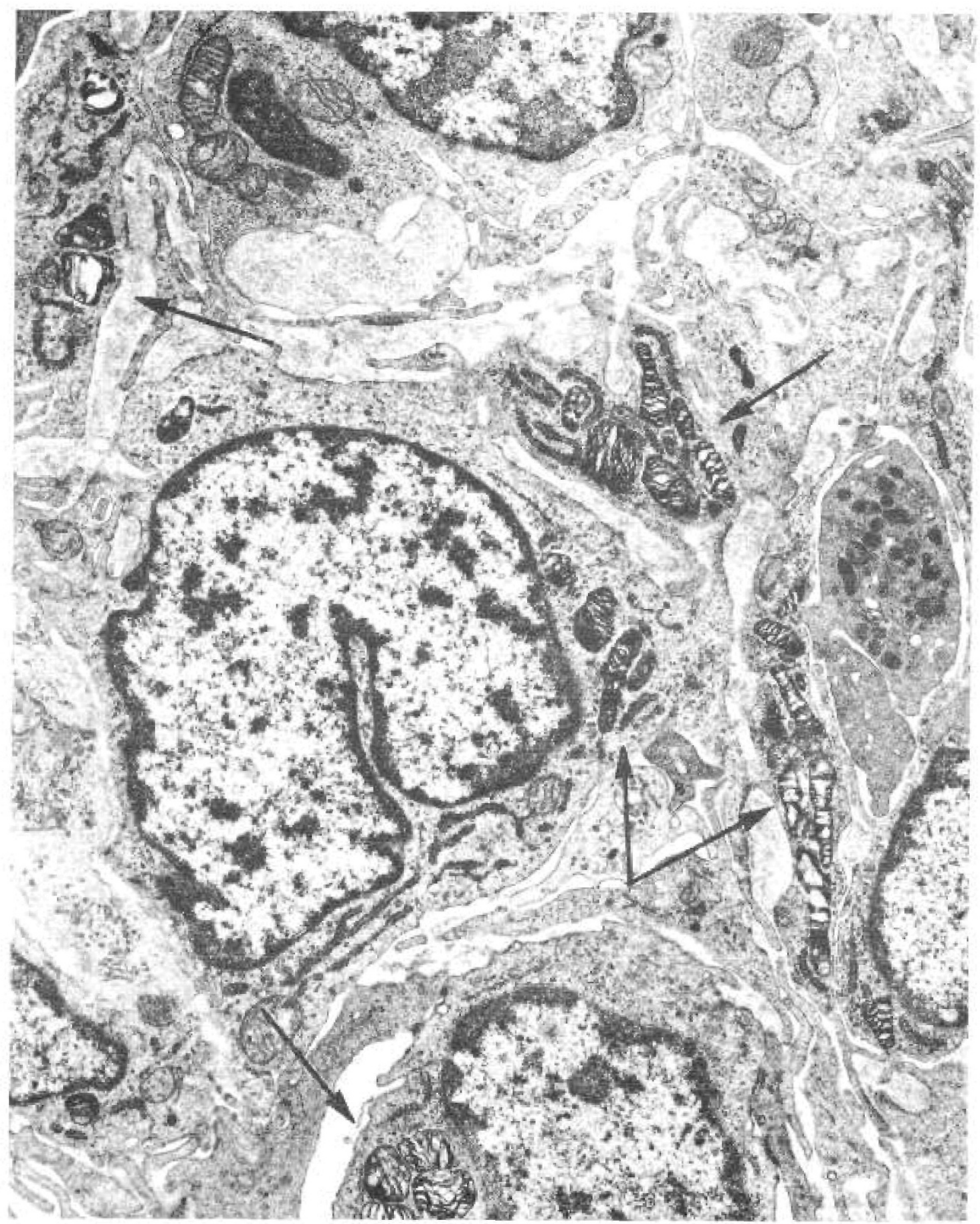

Fig. 4. Spleen of fetus with Niemann-Pick disease. Survey electron micrograph. Lipid cytosomes (arrows) with coarse densely stained membranes are scattered throughout the splenic reticulum and endothelial cells. $\times 13,000$.

and normal fetuses incubated either in medium without substrate or in medium containing sodium fluoride showed no reaction product with either azo dye or the Gomori method.

\section{Discussion and Conclusions}

In the fetus presented in this report, deficiency of sphingomyelinase activity in liver and brain and increase in sphingomyelin content of liver to levels com- 


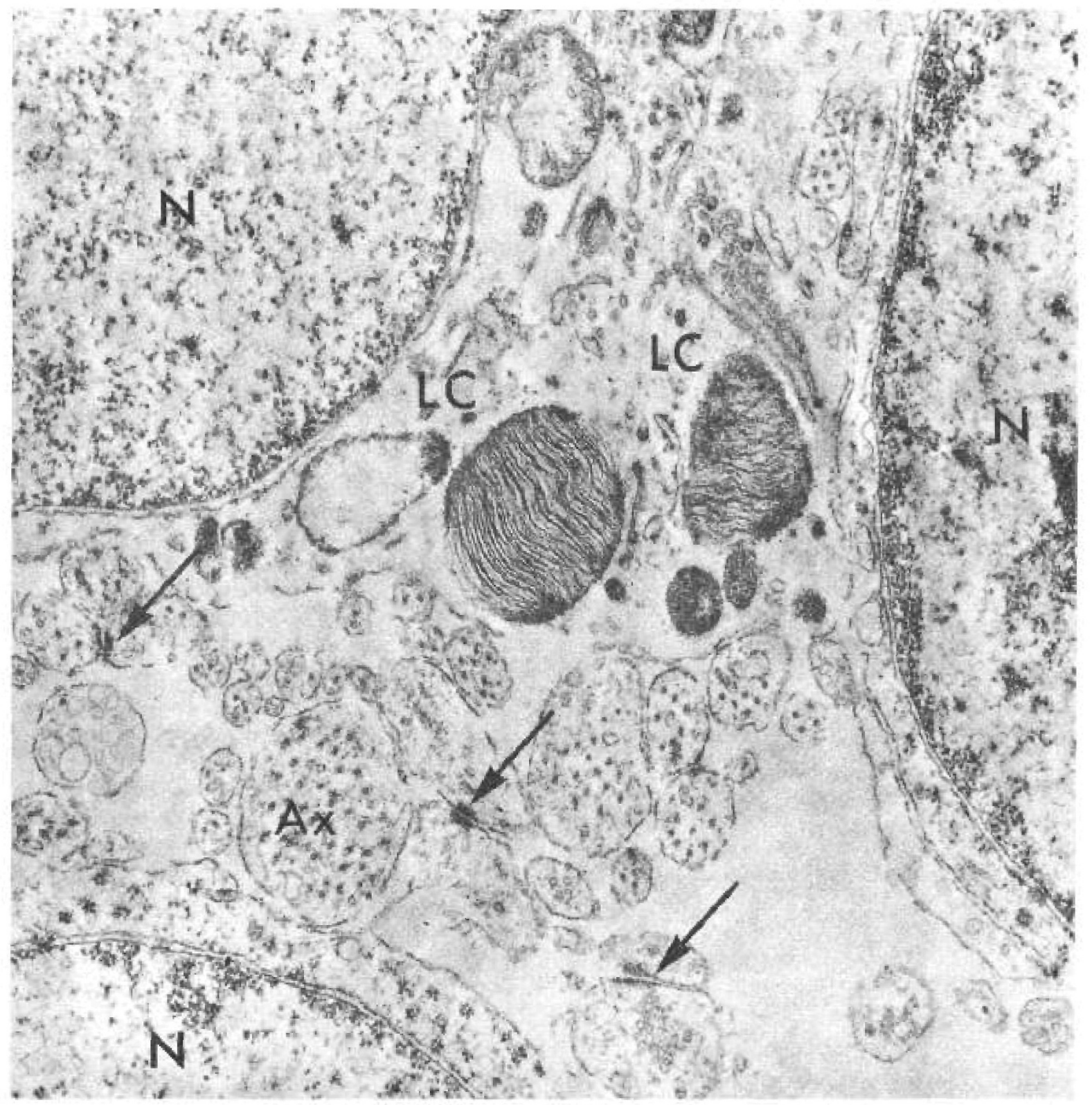

Fig. 5. Brain of fetus with Niemann-Pick disease. Lipid cytosomes $(L C)$ are visible within the neuronal cytoplasm in the basal ganglia. $A x$ : axonal process; $N$ : neuronal nucleus; arrows mark synaptic junctions. $\times 28,500$.

parable to those seen in tissues of affected children [17], together with a positive family history, clearly confirm the previous in vitro diagnosis of NPD. Several morphological findings indicate that by 19 gestational weeks, many of the characteristic features of NPD are present. These include cellular enlargement with cytoplasmic vacuolization and eccentric nuclei on light microscopy, increased deposition of phospholipids demonstrated by lipid histochemistry, and in- creased acid phosphatase reaction product by enzyme histochemistry when compared with control normal fetal liver and spleen. On electron microscopy, the LC's characteristic of sphingolipid storage were observed in liver, spleen, cerebral vessels and occasional neurons. In contrast to the elevated levels observed in affected infants, the cholesterol content of the NPD fetal liver was normal. This suggests that the primary defect in NPD is limited to sphingomyelin catabolism 


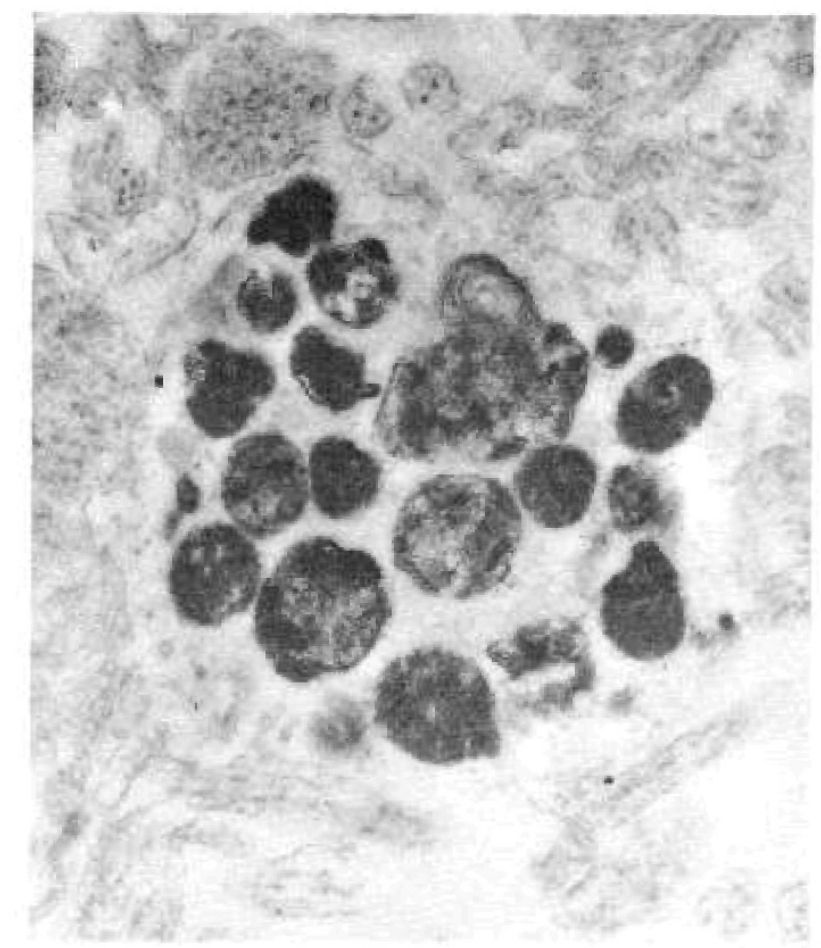

Fig. 6. Brain of fetus with Niemann-Pick disease. Dense bodies, some with membranous substructure, can be observed within a swollen axonal process in the basal ganglia. $\times 23,500$.

and that the increased levels of cholesterol seen later in the disease may be secondary to the disordered sphingolipid metabolism.

Only a few observations have been made on cases of presumed or documented pre- or neonatal NiemannPick disease. The mild cytoplasmic enlargement of liver and spleen cells and the absence of typical NPD foam cells in the present case differ from the light microscopic observations of Leal in the only previous report of early fetal NPD [23]. However, the diagnosis in Leal's case, a 5-month spontaneously aborted fetus, is uncertain. It was based histologically on the presence of numerous foam cells with vacuolated cytoplasm and eccentric nuclei in spleen, adrenals, liver and placenta, but there was neither a positive family history, histochemical staining for lipids, nor biochemical analysis of the tissues.

The spleen, lymphoid tissue, and adrenal cortex of a full term stillborn infant described by Burne [11] were heavily infiltrated by typical NPD foam cells. Unlike the present case, hepatocyte cytoplasm was distended with glycogen rather than phospholipid. Brain involvement was limited to the pons in which neuronal cytoplasm was swollen and vacuolated, and his- tochemical examination revealed acid hematein-positive phospholipid in the ballooned pontine neurons and in splenic foam cells. Biochemical studies showed an increase in sphingomyelin in brain, kidneys, and spleen. The findings of major visceral involvement with only minor central nervous system changes in a full term NPD infant parallels the earlier manifestations observed in the present case as well as the clinical presentation of this disease.

Results of lipid stains in the present case are similar to those reported previously $[3,19,21,25]$ in which the majority of NPD cells stained positively with Sudan black, LFB, acid hematein, and OTAN. The increased acid phosphatase activity in NPD fetal hepatocytes resembles that reported in a liver biopsy from a case of NPD Type A [37] and in NPD foam cells [19], and the ultrastructural localization of acid phosphatase to lipid cytosomes is similar to that reported in post-natal cases [22, 39].

Ultrastructural evidence of marked lipid storage in liver, spleen, and cerebral vessels was based on the presence of numerous LC's characteristic of sphingolipid disorders. Similar cytosomes have been described previously in postnatal NPD $[2,17,22,24,25,34$, 37-39]. Less severe but nevertheless important neuronal abnormalities are indicated by the presence of a few typical LC's within neuronal perikarya, by the dense granular material within dilated endoplasmic reticulum cisternae of several neurons, and by distension of many axonal processes by large collections of dense bodies and altered mitochondria. Material found within the endoplasmic reticulum cisternae is similar to that reported in fetal neurons in Tay-Sachs disease and is interpreted as an early change in the evolution of lipid cytosomes [36]. Dense body accumulations within axons, similar to those in the present case, have been reported in NPD in myenteric plexus axons [2] and in the cytoplasm of dorsal root ganglion cells [24]. These abnormalities resemble axonal changes proximal to an injury [20] and may represent a significant though nonspecific response to neuronal injury. Although vessels were abnormal throughout brain and spinal cord, neuronal and axonal changes were found only in basal ganglia and more caudal levels of the neuraxis. This earlier involvement of the more mature central nervous system areas is similar to that observed in a full term stillborn infant [11] and in an 8-month-old infant [16] with NPD, as well as in a 21-wk fetus with Tay-Sachs disease [1] and a 20-wk fetus with Krabbe's disease [30].

Early fetal morphologic abnormalities have been 


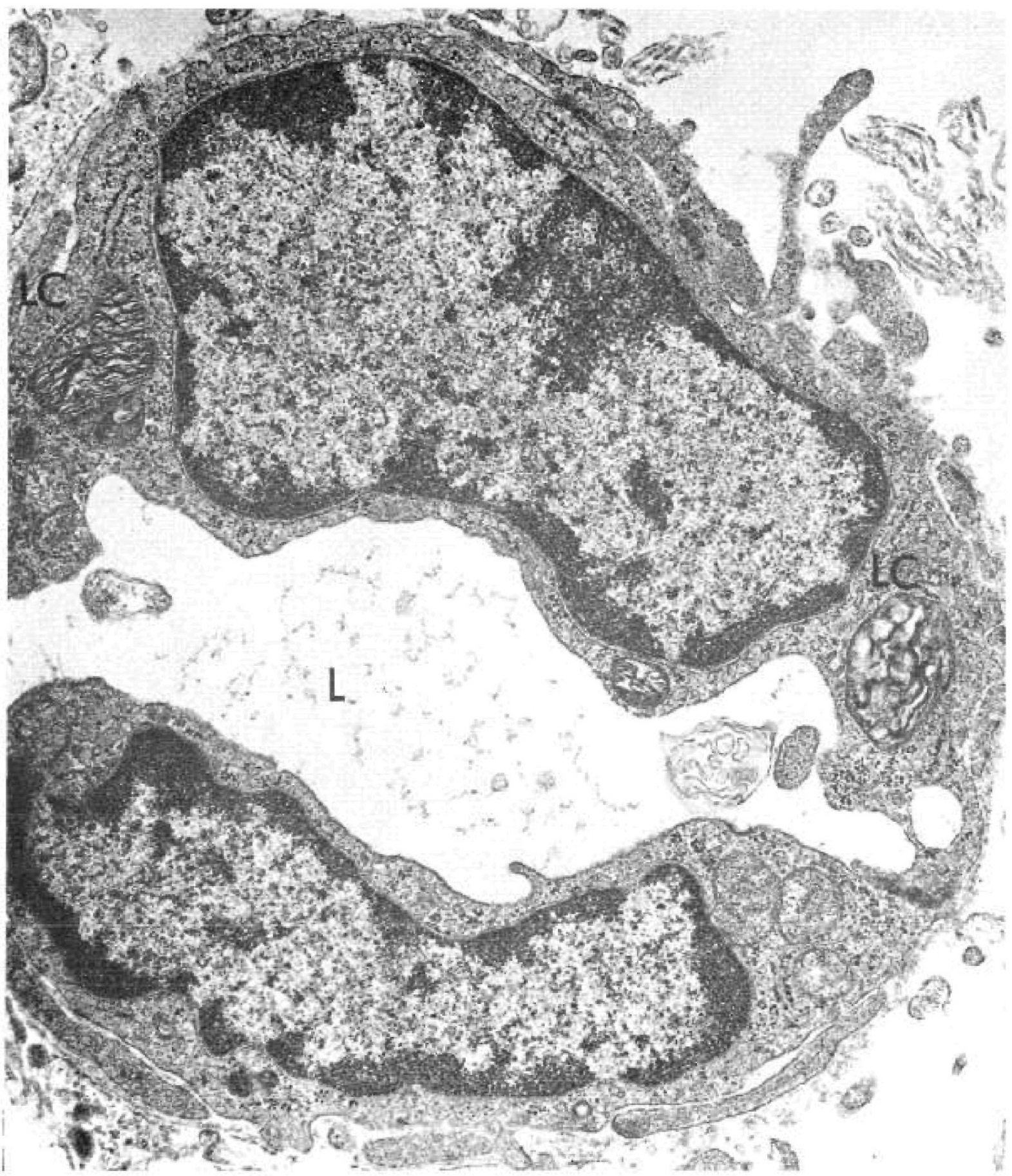

Fig. 7. Brain of fetus with Niemann-Pick disease. Lipid cytosomes $(L C)$ within the endothelial cytoplasm of a cerebral vessel. $L:$ lumen. $\times 33,000$.

found in three other hereditary neurodegenerative disorders, Tay-Sachs disease $[1,28]$, Gaucher's disease [29], and Krabbe's disease [30]. In Tay-Sachs fetuses described by Adachi et al. [1] and by O'Brien et al.
[28], LC's similar to those found in organs of the present case were observed in neurons at various levels of the neuraxis. In Adachi's case, major involvement appeared to be in spinal and brain stem neurons, antici- 
pating the early flaccid paralysis or atony common in this disease. In a 19-gestational week fetus with Gaucher's disease [29], increased deposition of sphingolipids was found in liver and spleen, anticipating, as in the present case, the hepatosplenomegaly which is the earliest clinical manifestation of this disorder. Similarly, in a 21-gestational week fetus with Krabbe's disease [30], formation of globoid cells seen in spinal cord and myelination delay in the caudal neuraxis antecede the spasticity and motor retardation which are the earliest signs of this disease. Thus, sphingolipid accumulation and morphologic findings in fetuses with four different metabolic diseases indicate that, although the infant with each disorder appears clinically normal at birth, the biochemical and pathologic manifestations are well advanced in organs destined to produce the earliest clinical signs.

Several authors $[4,12,32]$ have speculated on the use of "gene therapy" for inherited metabolic disorders related to specific enzyme deficiencies. NiemannPick disease, Tay-Sachs disease, Krabbe's disease and Gaucher's disease, all of which are related to deficient enzyme activities involved in sphingolipid catabolism, would be likely candidates for such gene-enzyme replacement therapy. However, unless an affected child has already appeared in a family, diagnosis of these diseases usually does not occur until several months after birth. The histologic and biochemical changes observed in these diseases in early gestation indicate that these disorders are well advanced by the time a postnatal diagnosis is made. Therefore the success of any therapy will depend on the extent of central nervous system involvement at the onset of therapy. Although the neuronal alterations observed on electron microscopy in the 19-wk NPD fetus are not as severe as those found in visceral organs, they raise the possibilities that the lesions may not be reversible and that prenatal or postnatal "gene therapy" may be ineffective. Therefore, for the foreseeable future, genetic counseling, detection of heterozygote carriers (as is now being done for Tay-Sachs disease) [7, 27], and prenatal diagnosis by examination of cultured amniotic cells appear to be the best tools for the prevention of these severe hereditary neurologic disorders.

\section{References and Notes}

1. Adachi, M., Toril, J., Schneck, L., and Volk, B. W.: The fine structure of fetal Tay-Sachs disease. Arch. Pathol., 91: 48 (1971).

2. Adachi, M., Volk, B. W., Schneck, L., and Toril, J.: Fine structure of the myenteric plexus in various lipidoses. Arch. Pathol., 87: 228 (1969).
3. Adams, C. W. M.: Neurohistochemistry, pp. 51, 503. (E1sevier Publishing Co.; Amsterdam, 1965).

4. Aposhian, H. V.: The use of DNA for gene therapy-the need, experimental approach and implications. Perspect. Biol. Med., 14: 98 (1970).

5. Barka, T., and Anderson, P. J.: Histochemistry: Theory, Practice and Bibliography, p. 242 (Harper \& Row, New York, 1963).

6. Brady, R. O., Gal, A. E., Bradley, R. M., Martensson, E., Warshaw, A. L., and Laster, L.: Enzymatic defect in Fabry's disease. Ceramidetrihexosidase deficiency. N. Eng. J. Med., 276: 1163 (1967).

7. Brady, R. O., Johnson, W. G., and Uhlendorf, B. W.: Identification of heterozygous carriers of lipid storage diseases: current status and clinical application. Amer. J. Med., 51: 423 (1971).

8. Brady, R. O., Kanfer, J. N., Mock, M. B., ANd Fredrickson, D. S.: The metabolism of sphingomyelin. II. Evidence of an enzymatic deficiency in Niemann-Pick disease. Proc. Nat. Acad. Sci. U.S.A., 55: 366 (1966).

9. Brady, R. O., Kanfer, J. N., And Shapiro, D.: The metabolism of glucocerebrosides. I. Purification and properties of a glucocerebroside-cleaving enzyme from splcen tissue. J. Biol. Chem., 240: 39 (1965).

10. Brady, R. O., O'Brien, J. S., Bradley, R. M., and Gal, A. E.: Sphingolipid hydrolases in brain tissue of patients with generalized gangliosidosis. Biochim. Biophys. Acta, 210: 193 (1970).

11. Burne, J. C.: Niemann-Pick disease in a foetus. J. Pathol. Bacteriol., 66: 473 (1953).

12. Davis, B. D.: Prospects for genetic intervention in man. Science, 170: 1279 (1970).

13. Dittmer, J. C., and Lester, R. L.: A simple, specific spray for the detection of phospholipids on thin-layer chromatograms. J. Lipid Res., 5: 126 (1964).

14. Epstein, C. J., Brady, R. O., Schneider, E. L., Bradley, R. M., and Shapiro, D.: In utero diagnosis of Niemann-Pick disease. Amer. J. Hum. Genet., 23: 533 (1971).

15. Ericsson, J. L. E., And Trump, B. F.: Observations on the application to electron microscopy of the lead phosphate technique for the demonstration of acid phosphatase. Histochemie, $4: 470$ (1965).

16. Ivemark, B. I., Svennerholm, L., Thoren, C., And Tunell, R.: Niemann-Pick disease in infancy: report of two siblings with clinical, histologic and chemical studies. Acta Paediat. Scand., 52: 391 (1963).

17. Kamoshita, S., Aron, A. M., Suzuki, K., and Suzuki, K.: Infantile Niemann-Pick disease: a chemical study with isolation and characterization of membranous cytoplasmic bodies and myelin. Amer. J. Dis. Child., 117: 379 (1969).

18. Kanfer, J. N., Young, O. M., Shapiro, D., and Brady, R. O.: The metabolism of sphingomyelin. I. Purification and properties of a sphingomyelin-cleaving enzyme from rat liver tissue. J. Biol. Chem., 241: 1081 (1966).

19. LAKe, B. D.: A histochemical study of Gaucher's disease and Niemann-Pick's disease. J. Royal Micro. Soc., 86: 417 (1967).

20. LAMperT, P. W.: A comparative electron microscopic study of reactive, degenerating, regenerating, and dystrophic axons. J. Neuropathol. Exp. Neurol., 26: 345 (1967).

21. Landing, B. W., O’Brien, J. S., ANd Wilcox, L. G.: Luxol-dye staining in lipid storage diseases. In: S. M. Aronson and R. 
W. Volk: Inborn Disorders of Sphingolipid Metabolism, p. 121. (Pergamon Press, Oxford, 1967).

22. Lazarus, S. S., Vethamany, V. G., Schneck, L., and Volk, B. W.: Fine structure and histochemistry of peripheral blood cells in Niemann-Pick disease. Lab. Invest., 17: 155 (1967).

23. Leal, A.: Niemann Pick en un huevo de 5 meses. Aborto por desprendimiento placentario. Obstet. Ginecol. Latino-Amer., 11: 277 (1953).

24. Luse, S.: The fine structure of the brain and other organs in Niemann-Pick disease. In: S. M. Aronson and B. W. Volk: Inborn Disorders of Sphingolipid Metabolism, p. 93. (Pergamon Press, Oxford, 1967).

25. Lynn, R., AND TeRrY, R.: Lipid histochemistry and electron microscopy in adult Niemann-Pick disease. Amer, J. Med., 37: 987 (1964).

28. Martin, J. H., Lynn, J. A., and Nickey, W. M.: A rapid polychrome stain for epoxy-embedded tissue. Amer. J. Clin. Pathol., 46: 250 (1966).

27. O'Brien, J. S., Okada, S., Chen, A., And Fillerup, D. L.: TaySachs disease: detection of heterozygotes and homozygotes by serum hexosaminidase assay. New Eng. J. Med., 283: 15 (1970).

28. O’Brien, J. S., Okada, S., Fillerup, D. L., Veath, M. L., Adornato, B., Brenner, P. H., and Leroy, J. G.: Tay-Sachs disease: prenatal diagnosis. Science, 172: 61 (1971).

29. Schneider, E. L., Ellis, W. G., Brady, R. O., McCulloch, J. R., AND Epstein, C. J.: Prenatal Gaucher's disease: in utero diagnosis and fetal pathology. Submitted for publication, 1972.

30. Schneider, E. L., Ellis, W. G., Suzuki, K., McCulloch, J. R., And Epstein, C. J.: Prenatal Krabbe's disease. In preparation, 1972 .

31. Schulz, D. M., Grordano, D. A., And Schulz, D. H.: Weights of organs of fetuses and infants. Arch. Pathol., 74: 244 (1962).

32. Sinsheimer, R. L.: The prospect for designed genetic change. Amer. Sci., 57: 134 (1969).

33. Sloan, H. R., Uhlendorf, B. W., Kanfer, J. N., Brady, R. O., AND Fredrickson, D. S.: Deficiency of sphingomyelincleaving enzyme activity in tissue cultures derived from patients with Niemann-Pick disease. Biochem. Biophys. Res. Commun., 34: 582 (1969).

34. Tanaka, Y., Brecher, G., And Fredrickson, D. S.: Cellules de la maladie de Niemann-Pick et de quelques autres lipoidoses. Nouv. Rev. Fr. Hematol., 3: 5 (1963).

35. Uhlendorf, B. W., Holtz, A. I., Mock, M. B., ANd Fredrickson, D. S.: Persistence of a metabolic defect in tissue cultures derived from patients with Niemann-Pick disease. In: S. M. Aronson and B. W. VoLK: Inborn Disorders of Sphingolipid Metabolism, p. 443. (Pergamon Press, Oxford, 1967).

36. Volk, B. W., Adachi, M., Friedland, J., Schneck, L., ANd VALENTI, C.: Early evolution of cytoplasmic inclusion bodies in Tay-Sachs disease. Proc. Soc. Exp. Biol. Med., 135: 836 (1970).

37. Volk, B. W., and Wallace, B. J.: The liver in lipidosis: an electron microscopic and histochemical study. Amer. J. Pathol., 49: 203 (1966).

38. Wallace, B. J., Schneck, L., Kaplan, H., and Volk, B. W.: Fine structure of the cerebellum of children with lipidoses. Arch. Pathol., 80: 466 (1965).

39. Wallace, B. J., Volk, B. W., Schneck, L., and Kaplan, H.: Fine structural localization of two hydrolytic enzymes in the cerebellum of children with lipidoses. J. Neuropathol. Exp. Neurol., 25: 76 (1966).

40. The opinions or conclusions stated in this paper are those of the authors (WGE and JRM) and are not to be construed as official or as necessarily reflecting the policy of the California Department of Mental Hygiene.

41. RCA EMU 3-F, Hitachi HS-7 and HU-11 electron microscopes were used through the generous cooperation of Drs. C. Piel, J. Goodman, T. Hoshino, and M. N. Hart.

42. We wish to thank Dr. S. Friedman for performing the amniocentesis; Miss N. Raab, Mrs. I. Robley, and Miss S. Colt for skilled technical assistance; Dr. C. Skinner of Sacramento for referring this patient to our clinic; and Dr. N. Malamud for review of the manuscript.

43. Dr. E. L. Schneider is a recipient of a postdoctoral fellowship from the Maternal and Child Health Service, United States Public Health Service. Dr. W. G. Ellis is the recipient of a grant from the University of California Cancer Research Fund. Dr. C. J. Epstein is the recipient of a Research Career Development Award from the National Institute of Child Health and Human Development, National Institutes of Health.

44. This work was supported by grants from the John A. Hartford Foundation, the National Foundation-March of Dimes, the National Institute of Neurological Diseases and Stroke (Grant no. NS05227-12), and the University of California Cancer Research Fund.

45. Requests for reprints should be addressed to: Dr. C. J. EPsTeIN, Department of Pediatrics, University of California, San Francisco, California 94122 (USA).

46. Accepted for publication April 5, 1972. 